\title{
Employment, health outcomes, and life satisfaction after spinal cord injury: comparison of veterans and nonveterans
}

\author{
Kelli W. Gary ${ }^{1} \cdot{\text { Yue } \mathrm{Cao}^{2} \cdot \text { Stephen P. Burns }}^{3,4} \cdot$ Scott D. McDonald ${ }^{5} \cdot$ James S. Krause $^{2}$ \\ Received: 8 October 2018 / Revised: 11 July 2019 / Accepted: 12 July 2019 / Published online: 6 August 2019 \\ (c) The Author(s), under exclusive licence to International Spinal Cord Society 2019
}

\begin{abstract}
Study design Retrospective cohort study.

Objective To explore differences between veterans and nonveterans with spinal cord injury (SCI) for employment, health, and satisfaction with life outcomes after controlling for demographic and injury characteristics.

Setting Hospitals in the Spinal Cord Injury Model System of care.

Methods A total of 9754 (85\% nonveterans and 15\% veterans) adults with traumatic SCI interviewed from 2000 and 2015 and completed follow-up years 1, 5, and 10 were included in this study. Employment status and the Craig Handicap Assessment and Reporting Technique-Short Form (CHART-SF) measured employment. The SF-36 for self-perceived health status, CHART-SF, and rehospitalization determined health outcomes. Satisfaction with life was measured by the Satisfaction with Life Scale (SWLS). Secondary data analyses using $\chi^{2}, t$-tests, and generalized estimating equations (GEEs) model to determine group differences with control of demographic and injury characteristics.

Results There were no significant differences for employment and SWL between nonveterans and veterans. There were some differences in health outcomes; whereas, veterans had better physical independence and mobility compared with nonveterans.

Conclusion Interventions for both groups should target adults with a disability from SCI, be customized for varying levels of injury that address differences in healthcare systems, demographic backgrounds, economic resources, disincentives, and motivation.
\end{abstract}

\section{Introduction}

Spinal cord injury (SCI) may have a tremendous impact on individuals, family, and society at large. There are $\sim 282,000$ persons living in the US with SCI [1] that have a myriad of

Kelli W. Gary

williamsjonk@vcu.edu

1 Department of Occupational Therapy, Virginia Commonwealth University, Richmond, VA, USA

2 College of Health Professions, Medical University of South Carolina, Charleston, SC, USA

3 Spinal Cord Injury Service, VA Puget Sound Health Care System, Seattle, WA, USA

4 Department of Rehabilitation Medicine, University of Washington, Seattle, WA, USA

5 Psychology Section (116B), Mental Health Service, Hunter Holmes McGuire VA Medical Center, Richmond, VA, USA long-term medical complications requiring extensive medical care and rehospitalization [2]. Veterans account for a large proportion of those living with either traumatic SCI or spinal cord disorders (SCI/D), such as spinal stenosis, multiple sclerosis, and transverse myelitis [3]. Difficulties associated with SCI for nonveterans and veterans alike involve increased risk for diminished life expectancy [4], secondary health conditions [5], mental health disorders [6], decreased community participation [7], and decreased subjective wellbeing [8]. However, there are some differences between veterans and nonveterans that may influence adjustment and functional outcomes after SCI. For example, high rates of posttraumatic stress syndrome [9], the need to readjust to civilian life and the burden of not being able to serve [10] increases the risk for poorer health and healthy behaviors [11], mental health problems and substance use [12]. These factors support the examination of various functional outcomes for veterans compared with nonveterans with SCI.

There is a paucity of the published literature comparing veterans and nonveterans with SCI in employment, health, 
Table 1 Frequency of unique participants and follow-up observations by veteran status

\begin{tabular}{llcc}
\hline & $\begin{array}{c}\text { Number of nonveteran } \\
\text { (Row \%) }\end{array}$ & $\begin{array}{c}\text { Number of veteran } \\
\text { (Row \%) }\end{array}$ & $\begin{array}{c}\text { Total participants } \\
\text { (total follow-up observations) }\end{array}$ \\
\hline Participants with one follow-up & $4467(81.3)$ & $1028(18.7)$ & 5495 \\
Participants with two follow-ups & $2810(89.1)$ & $345(10.9)$ & 3155 \\
Participants with three follow-ups & $1001(90.7)$ & $103(9.3)$ & 1104 \\
Total & $8278(84.9)$ & $1476(15.1)$ & 9754 \\
\hline
\end{tabular}

and satisfaction with life (SWL) outcomes. One study reported that veterans with SCI had more chronic comorbid conditions over the years, lower overall physical health, and were less likely to be employed compared with civilians with SCI [13]. LeVela et al. [14] compared veterans with SCI with general veteran population and general population for health outcomes and found the odds of having a stroke were higher in veterans with SCI than both comparison groups and after controlling for demographic and risk factors and SCI was independently associated with stroke. Compared with nonveterans with SCI, veteran counterparts reported higher levels of catastrophizing and pain, and lower levels of social integration and productive activity [15]. The SWL outcome studies after SCI examined veterans and did not have a comparison group but had interesting results for that population. Studies found higher cognitive function, social integration, self-perceived independence, social support, less pain, and fewer secondary impairments were positively associated with SWL after SCI [16-18].

Since very few studies have compared veterans and nonveterans in the US with SCI related to employment, health, and SWL, there is clear justification for examining these outcomes for both groups. Given that SCI has a deleterious effect on both veterans and nonveterans that yields significant health and psychosocial outcomes, cross comparison of these two groups is warranted. The few studies that do compare veterans and nonveterans with SCI had either small sample sizes or made comparisons with different data sources. Some studies that examined SWL were conducted outside the US. Moreover, more effort is needed to address needs of veterans as more have survived once fatal injuries from recent wars as they age with significant impairment [19]. It is possible, that these comparisons will uncover predictors more relevant to veterans and provide evidence to substantiate differences between veterans and nonveterans being treated in the community by SCI providers.

Our purpose was to utilize a database with large samples to explore differences in outcomes among veterans and nonveterans with SCI. Specifically, we aim to determine what differences exist between adult veterans and nonveterans treated within the Spinal Cord Injury Model
System (SCIMS) program in terms of employment, health, and SWL outcomes. We hypothesize veterans and nonveterans treated within the SCIMS will significantly differ for employment, health, and SWL variables when simultaneously controlling for demographic and injury characteristics.

\section{Methods}

\section{Data source}

The National Spinal Cord Injury Database (NSCID) has captured data on new SCI cases from 1972 to present. The NSCID provided retrospective cross-sectional data of patients who were enrolled in the SCIMS program funded by Health and Human Services' National Institute on Disability, Independent Living, and Rehabilitation Research. The participants have all received either acute care, inpatient rehabilitation, and/or systematic outpatient, or day rehabilitation. To be enrolled in SCIMS program and included in NSCID: (1) patients had to be treated at SCIMS facility within 1 year of SCI onset, (2) have clinically discernible degree of neurological impairment after a traumatic event, (3) completed informed consent, and (4) reside in the geographic catchment areas of SCIMS facility at time of injury [20].

\section{Data collection}

From the NSCID, 8278 nonveterans and 1476 veterans primarily diagnosed with traumatic SCI and treated at any of the SCIMS centers between October 1, 2000 and September 2015 were compared for differences in employment, health, and SWL outcomes. Participants were categorized as veterans-those who identified either use of the US Veterans Health Administration health care services since SCI onset, or did not receive services but still classified as a veteran, or those who identified as nonveteran. Of note, individuals who have onset of SCI while active duty service members (injures related or unrelated to combat) typically receive initial SCI rehabilitation at veteran administration (VA) hospitals, so 
Table 2 Patient demographic and injury characteristics

\begin{tabular}{|c|c|c|c|c|}
\hline Demographic characteristics & $\begin{array}{l}\text { Overall } \\
n=9754\end{array}$ & $\begin{array}{l}\text { Nonveteran } \\
n=8278\end{array}$ & $\begin{array}{c}\text { Veterans } \\
n=1476\end{array}$ & Statistics* \\
\hline Mean age at injury \pm SD (y) & $\begin{array}{l}36.0 \pm 13.8 \\
\mathrm{n}\end{array}$ & $\begin{array}{l}34.8 \pm 13.5 \\
\mathrm{Col} \%\end{array}$ & $\begin{array}{l}42.6 \pm 13.8 \\
\mathrm{Col} \%\end{array}$ & $p<0.01$ \\
\hline \multicolumn{5}{|l|}{$\operatorname{Sex}(\%)$} \\
\hline Male & 7773 & 77.7 & 91.0 & \multirow[t]{3}{*}{$p<0.01$} \\
\hline Female & 1979 & 22.3 & 9.0 & \\
\hline Unknown, transgender ${ }^{\mathrm{a}}$ & 2 & & & \\
\hline \multicolumn{5}{|l|}{ Race/ethnicity (\%) } \\
\hline Hispanic & 988 & 10.5 & 8.1 & \multirow[t]{4}{*}{$p<0.01$} \\
\hline Non-Hispanic White & 6075 & 61.5 & 66.6 & \\
\hline Non-Hispanic Black & 2306 & 23.9 & 22.2 & \\
\hline Non-Hispanic other & 385 & 4.1 & 3.1 & \\
\hline \multicolumn{5}{|l|}{ Highest level of Ed at injury (\%) } \\
\hline Less than High School & 392 & 4.5 & 2.6 & \multirow[t]{5}{*}{$p<0.01$} \\
\hline Secondary Ed (some or completed) & 7027 & 76.3 & 75.4 & \\
\hline Postsecondary Ed (some or completed) & 1416 & 15.0 & 17.3 & \\
\hline Graduate (some or completed) & 390 & 4.1 & 4.7 & \\
\hline Other/unknown ${ }^{\mathrm{a}}$ & 529 & & & \\
\hline \multicolumn{5}{|l|}{ Injury characteristics } \\
\hline \multicolumn{5}{|l|}{ Etiology (\%) } \\
\hline Vehicular accident & 4428 & 45.8 & 43.3 & \multirow[t]{5}{*}{$p<0.01$} \\
\hline Violence & 1554 & 16.6 & 12.1 & \\
\hline Sports & 898 & 9.6 & 7.2 & \\
\hline Falls/flying objects & 2379 & 23.1 & 31.9 & \\
\hline Other (pedestrian, med/surg, other) & 495 & 4.9 & 5.5 & \\
\hline \multicolumn{5}{|l|}{ Neurological impairment at D/C (\%) } \\
\hline Paraplegia, incomplete & 1790 & 19.3 & 18.8 & \multirow[t]{8}{*}{$p<0.01$} \\
\hline Paraplegia, complete & 2535 & 27.7 & 24.2 & \\
\hline Paraplegia minimal deficit & 35 & 0.3 & 0.6 & \\
\hline Tetraplegia, incomplete & 3237 & 33.7 & 40.3 & \\
\hline Tetraplegia, complete & 1697 & 18.7 & 15.3 & \\
\hline Tetraplegia, minimal deficit & 42 & 0.4 & 0.9 & \\
\hline Normal (some minimal deficits) $^{\mathrm{a}}$ & 6 & & & \\
\hline Unknown/not done ${ }^{\mathrm{a}}$ & 412 & & & \\
\hline
\end{tabular}

$* \chi^{2}$ test applies to categorical variables, and $t$-test to continuous variables

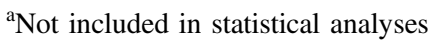

veterans included in this study predominantly had onset of SCI after leaving military service. Inclusion criteria were: (1) had available veteran status data, (2) injured between 2000 and 2015, (3) completed follow-up for years 1, 5, and 10, and (4) between ages of 18 and 70 years old. Participants were excluded if they were lost before year 1 follow-up or had missing veteran status data. The follow-up data were collected via in person or telephone interviews, and mail surveys. Table 1, highlights the frequency of unique veteran and nonveteran participants' observations for each follow-up year and by veteran status.

\section{Outcome measures}

\section{Employment status}

Employment was categorized as those currently competitively employed in the labor market versus those who are not competitively employed. Therefore, those who identified as unemployed, homemaker, on-the-job training, sheltered workshop, retired, and other unclassified (i.e., volunteered, medical leave, illegal employment, and paid under the table) were grouped together. This distinction was made to objectively differentiate between those 
Table 3 GEE model for employment status (employed vs. others)

\begin{tabular}{llllr}
\hline & OR & \multicolumn{2}{l}{$95 \%$ OR } & $p$-value \\
\hline Veteran (ref = Nonveteran) & 0.95 & 0.81 & 1.12 & 0.55 \\
Male (ref = female) & 1.30 & 1.13 & 1.48 & $<0.01$ \\
Non-Hispanic White (ref = others) & 2.11 & 1.86 & 2.40 & $<0.01$ \\
College or higher (ref = others) & 3.93 & 3.47 & 4.46 & $<0.01$ \\
Age at injury & 0.98 & 0.97 & 0.98 & $<0.01$ \\
Violence (ref = others) & 0.45 & 0.37 & 0.56 & $<0.01$ \\
Vehicular accident (ref = others) & 0.97 & 0.87 & 1.09 & 0.62 \\
c1-4 (ref = others) & 0.44 & 0.38 & 0.50 & $<0.01$ \\
c5-8 (ref = others) & 0.63 & 0.56 & 0.72 & $<0.01$ \\
Complete (ref = incomplete) & 0.61 & 0.55 & 0.68 & $<0.01$ \\
Year 5 (ref = year 1) & 1.68 & 1.54 & 1.83 & $<0.01$ \\
Year 10 (ref = year 1) & 2.22 & 2.01 & 2.45 & $<0.01$ \\
\hline
\end{tabular}

employed and not employed for any reason at the time of the study.

\section{Self-perceived health status}

Self-perceived health status comes from SF-36 physical and mental health summary scales and is measured by a single item asking "In general, would you say that your health is Excellent, Very Good, Good, Fair, or Poor?" [21]. It was rated on an ordinal scale that ranges from 1 (Excellent) to 5 (Poor). Responses that were "Fair" or "Poor" were dichotomized into fair and poor health versus others. The SF-36 scales have strong psychometrics for good interpretation of physical health [22].

\section{Craig handicap assessment and reporting technique-short form}

The CHART has 19 items where highest total score of 100 indicate no handicap for physical independence, cognitive independence, mobility, occupation, social integration, and economic self-sufficiency [23]. These areas are dimensions of handicap at the societal level. The CHART is a psychometrically sound assessment with high reliability and good validity [24].

\section{Rehospitalization}

Rehospitalization numbers represent the mean number of times within 12 months patients were hospitalized.

\section{Life satisfaction}

The Satisfaction with Life Scale (SWLS) has five items to self-report life satisfaction [25]. The SWLS can either have ordinal measurements that range from 1 (strongly disagree) to 7 (strongly agree) [25]. The SWLS has good psychometrics [26].

\section{Statistical analyses}

First, to compare demographic and injury characteristics of nonveterans and veterans, non-parametric $\chi^{2}$ statistics were used to determine between-group differences for all categorical variables and $t$-tests were used with continuous variables. An $\alpha$ level of 0.05 or less determined significance. For the multivariate analyses, the employment was a binary outcome repeatedly measured. We applied the generalized estimating equation (GEE) method for the multivariate longitudinal analyses. The method used quasilikelihood to estimate the regression coefficients for the longitudinal data [27]. The employment status was a binary outcome and we used GEE with a logit link. For all the other outcomes, we used Gaussian GEE.

\section{Results}

\section{Description of the sample}

Table 1 describes the frequency of unique participants and total follow-up observations. In addition, it highlights the frequency of unique participants among veterans and nonveterans with SCI. Of the total 9754 unique participants, there were 15,117 observations. Approximately $15 \%$ of those unique participants identified as veterans. Table 2 describes the demographic and injury characteristics of the sample. Males predominate in this sample (79.7\%). The mean age of all participants at time of injury was 36 years. Most participants were non-hispanic White $(62.2 \%)$, had some or completed high school $(72 \%)$, injured in a vehicular accident $(45.3 \%)$, and had incomplete tetraplegia (33.2\%). There were significant differences between veterans and nonveterans with regards to all demographic and injury characteristics. Veterans were significantly older, more likely to be male, had racial/ethnic status of nonHispanic White, and had higher levels of education. For injury characteristics, veterans had more injuries related to falls and flying objects compared with nonveterans, who had more injuries from vehicular and violent incidents. In addition, veterans presented with more incomplete tetraplegia and significantly less complete paraplegia SCIs compared with nonveteran counterparts.

\section{Employment status}

Employment status was assessed at 1, 5, and 10 years and controlled for demographic and injury factors using the GEE model to generate odds ratios obtained for the total 
Table 4 GEE models for continuous outcomes

\begin{tabular}{|c|c|c|c|c|c|c|}
\hline & \multicolumn{2}{|c|}{ Self-perceived health } & \multicolumn{2}{|c|}{$\begin{array}{l}\text { Physical } \\
\text { independence }\end{array}$} & \multicolumn{2}{|l|}{ Mobility } \\
\hline & Coefficient & $p$-value & Coefficient & $p$-value & Coefficient & $p$-value \\
\hline Intercept & 3.59 & $<0.01$ & 92.69 & $<0.01$ & 91.39 & $<0.01$ \\
\hline Veteran $($ ref $=$ nonveteran $)$ & 0.03 & 0.26 & 3.12 & $<0.01$ & 1.84 & 0.01 \\
\hline Male $($ ref $=$ female $)$ & 0.02 & 0.45 & 2.91 & $<0.01$ & 3.38 & $<0.01$ \\
\hline Non-Hispanic White (ref $=$ others) & 0.16 & $<0.01$ & 4.92 & $<0.01$ & 7.72 & $<0.01$ \\
\hline College or higher $($ ref $=$ others $)$ & 0.33 & $<0.01$ & 4.22 & $<0.01$ & 9.66 & $<0.01$ \\
\hline Age at injury & -0.02 & $<0.01$ & -0.25 & $<0.01$ & -0.47 & $<0.01$ \\
\hline Violence (ref $=$ others) & -0.16 & $<0.01$ & -2.17 & 0.04 & -5.49 & $<0.01$ \\
\hline Vehicular accident (ref $=$ others) & -0.01 & 0.70 & 1.44 & 0.04 & -0.60 & 0.26 \\
\hline $\mathrm{c} 1-4(\mathrm{ref}=$ others $)$ & 0.00 & 0.92 & -30.59 & $<0.01$ & -12.48 & $<0.01$ \\
\hline $\mathrm{c} 5-8(\mathrm{ref}=$ others $)$ & 0.04 & 0.14 & -16.53 & $<0.01$ & -4.57 & $<0.01$ \\
\hline Complete (ref $=$ incomplete $)$ & 0.07 & $<0.01$ & -16.70 & $<0.01$ & -9.88 & $<0.01$ \\
\hline Year $5($ ref $=$ year 1$)$ & 0.01 & 0.47 & 6.15 & $<0.01$ & 2.42 & $<0.01$ \\
\hline Year $10($ ref $=$ year 1$)$ & -0.03 & 0.11 & 7.19 & $<0.01$ & 1.62 & $<0.01$ \\
\hline
\end{tabular}

Table 5 GEE models for continuous outcomes (cont.)

\begin{tabular}{|c|c|c|c|c|c|c|c|c|}
\hline & \multicolumn{2}{|l|}{ Occupation } & \multicolumn{2}{|c|}{ Social integration } & \multicolumn{2}{|c|}{$\begin{array}{l}\text { Rehospitalization num- } \\
\text { ber }\end{array}$} & \multicolumn{2}{|c|}{ Life satisfaction } \\
\hline & Coefficient & $p$-value & Coefficient & $p$-value & Coefficient & $p$-value & Coefficient & $p$-value \\
\hline Intercept & 82.37 & $<0.01$ & 93.36 & $<0.01$ & 0.11 & $<0.01$ & 23.13 & $<0.01$ \\
\hline Veteran $($ ref $=$ nonveteran $)$ & 0.38 & 0.71 & 1.10 & 0.11 & -0.03 & 0.21 & 0.40 & 0.09 \\
\hline Male $($ ref $=$ female $)$ & -3.99 & $<0.01$ & 0.09 & 0.86 & -0.04 & 0.07 & 0.03 & 0.90 \\
\hline Non-Hispanic White (ref $=$ others) & 10.64 & $<0.01$ & 5.40 & $<0.01$ & 0.04 & 0.06 & 0.10 & 0.57 \\
\hline College or higher (ref $=$ others) & 13.69 & $<0.01$ & 8.46 & $<0.01$ & -0.09 & $<0.01$ & 1.81 & $<0.01$ \\
\hline Age at injury & -0.68 & $<0.01$ & -0.25 & $<0.01$ & 0.01 & $<0.01$ & -0.09 & $<0.01$ \\
\hline Violence (ref $=$ others) & -8.32 & $<0.01$ & -7.01 & $<0.01$ & 0.11 & $<0.01$ & -2.28 & $<0.01$ \\
\hline Vehicular accident (ref $=$ others $)$ & 0.04 & 0.95 & -0.30 & 0.54 & 0.03 & 0.05 & -0.09 & 0.62 \\
\hline $\mathrm{c} 1-4$ (ref = others) & -19.71 & $<0.01$ & -4.10 & $<0.01$ & 0.18 & $<0.01$ & -1.29 & $<0.01$ \\
\hline $\mathrm{c} 5-8$ (ref = others) & -9.29 & $<0.01$ & -1.01 & 0.06 & 0.06 & $<0.01$ & -0.79 & $<0.01$ \\
\hline Complete (ref = incomplete) & -9.31 & $<0.01$ & -1.21 & 0.01 & 0.27 & $<0.01$ & -1.24 & $<0.01$ \\
\hline Year $5($ ref $=$ year 1$)$ & 7.73 & $<0.01$ & -1.09 & $<0.01$ & -0.09 & $<0.01$ & 1.72 & $<0.01$ \\
\hline Year $10($ ref $=$ year 1$)$ & 6.99 & $<0.01$ & -1.28 & $<0.01$ & -0.10 & $<0.01$ & 2.54 & $<0.01$ \\
\hline
\end{tabular}

interviews (see Table 3 ). There were no significant differences for employment between nonveterans and veterans. Of note, odds of employment significantly increased if participants were male, non-Hispanic White, had a college education or higher, and interviewed at years 5 and 10 . Males had 1.3 greater odds of being employed compared with females. Non-Hispanic Whites had 2.1 times greater odds of being employed than other racial/ethnic groups. Those having a college education or higher had 3.93 times greater odds of employment than other lower education groups. Compared with year 1, participants interviewed at year 5 and year 10 had 1.68 and 2.22 greater odds of employment, respectively. In contrast, those who are older age at injury, had injuries caused by violence, and had cervical and complete injuries were less likely to be employed.

\section{Health and SWL outcomes over time}

In Table 4, the GEE model revealed that veterans are more likely to be physically independent and have increased mobility compared with nonveterans, in general. After controlling for demographic and injury characteristics, veterans were 3.12 points higher in physical independence score compared with nonveterans. For mobility score, veterans are 1.84 points higher than nonveterans. According to the 
CHART [23], veterans were more likely to have a routine and live more independently, and to move around in house as well as, use more independently use than nonveterans.

No other significant differences were found in occupation, social integration (other subscales of the CHART), self-perceived health, rehospitalization, and SWL outcomes (see Table 5).

\section{Discussion}

This study first compared demographic and injury characteristics between veterans and nonveterans with traumatic SCI from the SCIMS. The main purpose of the study was to examine primary outcomes of employment, health, and SWL outcomes for the sample. We hypothesize veterans and nonveterans treated within the SCIMS will significantly differ for health, employment, and SWL variables when simultaneously controlling for demographic and injury characteristics. The hypothesis was only partially supported. Although, we found differences in demographic and injury characteristics outcomes after controlling for those demographic and injury factors and there were limited differences in primary outcome variables.

Results related to demographic and injury characteristics are consistent with previous studies that compared veterans with SCI to other populations. Veteran groups are significantly older, more likely to be male, and have higher levels of education [11, 13, 14]. A different pattern was seen for injury characteristics in relation to previous research, which found veterans and nonveterans to be similar in level of SCI [11, 14]. We found that nonveterans were less likely to have motor-incomplete tetraplegia than veterans; however, there are probably selective factors, which make those with more severe injuries more likely to be treated in the SCI model system.

As the primary focus of our study, we described odds of employment status while controlling for demographic and injury factors. The one study, to our knowledge, that compared veterans and nonveterans related to employment noted that veterans were less likely to be employed at the time of interview and 5 years post [13]. Our study did not corroborate Hedricks et al.'s [13] findings. Although this previous study used assistive technology as a predictor of employment and Social Security Administration benefit data to adjust for potentially confounding factors, it was not clear if the analysis for major sociodemographic data collected and detailed injury characteristics of the study participants with SCI. There could be other reasons why significant differences were not detected between veterans and nonveterans. They both may have disincentives to work the following disabilities even though the reasons may be different [28, 29]. There were, however, some notable results with other variables. As conferred by empirical evidence, there is a greater likelihood of employment post injury for men compared with women $[30,31]$, those with college education or higher than lower levels [29, 30], and non-Hispanic Whites compared with other racial/ethnic groups [32]. However, Ottomanelli et al. [33] did not corroborate the same findings for educational attainment or race for veterans with SCI. In addition, veterans and nonveterans are less likely to be employed due to violence, lesions higher in the spinal cord and complete injuries and these and other critical factors are supported by the existing literature [31,34].

Another part of our study was to describe health outcomes as measured by the CHART, rehospitalization, and SWL scores while controlling for demographic and injury characteristics. There were some notable differences on the CHART; whereas, veterans had better physical independence and mobility compared with nonveterans. Although, to our knowledge, we are the first to compare veterans and nonveterans with SCI on CHART outcomes, Hedrick et al. [13] did compare veterans and civilians' functional limitations and noted that civilians with SCI had slightly lower functioning than veteran counterparts, but differences were not statistically significant. There are potentially some factors that support enhanced veterans outcomes. There are some unique programs to optimize function and increase mobility for veterans with disabilities that are provided by the VA SCI System of Care and associated programs to support community dwelling veterans [35]. Veterans with SCI that enrolled in NSCID could have access to more services that focus on physical independence and mobility than nonveterans with SCI.

\section{Implications}

Overall, these findings suggest that there are some differences between veterans and nonveterans, but this was found in a non-VA healthcare setting. Interventions for both veterans and nonveterans should target adults with a disability from SCI that are customized for varying levels of injury. It is important to consider how healthcare systems affect outcomes, as they will differ in terms of factors such as length of stay. However, because we utilize secondary data from the SCI model systems, we cannot directly compare healthcare systems based on our study. Secondly, it is important to address differences in demographic backgrounds, economic resources, disincentives, and motivation when customizing interventions for veterans and nonveterans with SCI.

\section{Limitations}

This study makes an important contribution to the literature comparing veterans and nonveterans with SCI. However, 
there are several limitations. First, the NSCID contains selfreport data and there is a possibility of recall errors in the accuracy and completeness of the information gathered. Second, veterans were treated for new injury in a SCI model system may be systematically different than those who are treated in VA hospitals. Therefore, the current findings particularly highlight these types of differences among those treated in SCI model systems and should be verified with additional research. Third, use of any existing data set limits the number of potential outcome variables. Fourth, because of the exploratory nature of the study, we ran numerous statistical tests, which raised the probability of type I error.

\section{Future research}

This study only scratches the surface of potential differences in outcomes between veterans and nonveterans. More research is needed to corroborate the small but significant findings from this study. Studies that rely on other datasets that include different insurance payers and healthcare systems would help to clarify any differences in outcomes and explanatory factors. The examination of other aspects of employment, not included in the SCI model systems data, would be useful (e.g., earnings or other indicators of quality employment). Lastly, intervention studies to promote outcomes for both veterans and nonveterans are clearly needed.

\section{Data archiving}

The datasets generated during and/or analyzed during the current study are available in the National Spinal Cord Injury Statistical Center [https://www.nscisc.uab.edu/ Public_Pages/Database] [36].

Funding The contents of this publication were developed with grants (grant nos 90SI5016 and 90SI5002) from the National Institute on Disability, Independent Living, and Rehabilitation Research (NIDILRR). NIDILRR is a Center within the Administration for Community Living (ACL), Department of Health and Human Services (HHS). The contents of this publication do not necessarily represent the policy of NIDILRR, ACL, HHS, and you should not assume endorsement by the Federal Government.

Author contributions KWG was responsible for developing the research idea, developing aims and objectives, searching the literature, extracting and analyzing the data, interpreting the results, creating the reference list, and writing the manuscript. YC was responsible for extracting and analyzing the data, writing sections of manuscript, and creating tables. SPB was responsible for interpreting the results and providing feedback on the manuscript. SDM was responsible for interpreting results and providing feedback on the manuscript. JSK was responsible for data access and retrieval, developing research idea, developing aims and objectives, interpreting results, providing feedback on the manuscript, and providing overall mentorship on entire project.

\section{Compliance with ethical standards}

Conflict of interest The authors declare that they have no conflict of interest.

Ethics statement We certify that all applicable institutional and governmental regulations concerning the ethical use of human volunteers for this database were followed before this information was used as secondary data to conduct this research.

Publisher's note: Springer Nature remains neutral with regard to jurisdictional claims in published maps and institutional affiliations.

\section{References}

1. Jain NB, Ayers GD, Peterson EN, Harris MB, Morse L, O'Connor $\mathrm{KC}$, et al. Traumatic spinal cord injury in the United States, 1993-2012. J Am Med Assoc. 2015;313:2236-43. https://doi.org/ 10.1001/jama.2015.6250.

2. Devivo MJ. Epidemiology of traumatic spinal cord injury: trends and future implications. Spinal Cord. 2012;50:365-72. https://doi. org/10.1038/sc.2011.178.

3. Department of Veteran Affairs. VA and spinal cord. https://www. va.gov/opa/publications/factsheets/fs_spinal_cord_injury.pdf. Accessed 25 Aug 2018.

4. Krause JS, Saunders LL. Health, secondary conditions, and life expectancy after spinal cord injury. Arch Phys Med Rehabil. 2011;92:1770-5. https://doi.org/10.1016/j.apmr.2011.05.024.

5. Adriaansen JE, Van Asbeck FWA, Lindeman E, Van Der Woude LHV, De Groot S, Post MWM. Secondary health conditions in persons with spinal cord injury for at least 10 years: design of a comprehensive long-term cross-sectional study. Disabil Rehabil. 2013;35:1104-10. https://doi.org/10.3109/096382288.2012.712196.

6. Saunders LL, Krause JS, Focht KL. A longitudinal study of depression in survivors of spinal cord injury. Spinal Cord. 2012;50:72-7. https://doi.org/10.1038/sc.2011.83.

7. Ullrich PM, Spungen AM, Atkinson D, Bombardier CH, Chen Y, Erosa NA, et al. Activity and participation after spinal cord injury: state-of-the-art report. Arch Phys Med Rehabil. 2012;49:155-274. https://doi.org/10.1682/JRRD.2010.06.0108.

8. Migliorini C, Callaway L, New P. Preliminary investigation into subjective well-being, mental health, resilience, and spinal cord injury. J Spinal Cord Med. 2013;36:660-5. https://doi.org/10. 1179/2045772313Y.0000000100.

9. Richardson LK, Frueh C, Acierno R. Prevalence estimates of combat-related post-traumatic stress disorder: critical review. Aust N Z J Psychiatry. 2010;44:4-19. https://doi.org/10.3109/ 00048670903393597.

10. Morin R, editor. For many injured veterans, a lifetime of consequences. Washington, DC: Pew Research Center. 2011. http://www.pewresearch.org/topics/military-and-veterans/2011.

11. Hoerster KD, Lehavot K, Simpson T, McFall M, Reiber G, Nelson KM. Health and health behavior differences: U.S. military, veterans, and civilian men. Am J Prev Med. 2010;43:483-9. https://doi.org/10.1016/j.amepre.2012.07.029.

12. Bray RM, Pemberton MR, Lane ME, et al. Substance use and mental health trends among U.S. military active duty personnel: key findings from the 2008 DoD Health Behavior Survey. Mil Med. 2010;175:390-9. https://doi.org/10.7205/MILMED-D-0900132.

13. Hedrick B, Pape TL, Heinemann AW, Ruddell JL, Reis J. Employment issues and assistive technology use for persons with 
spinal cord injury. J Rehabil Res Dev. 2006;43:185-98. https:// doi.org/10.1682/jrrd.2005.03.0062.

14. LaVela SL, Evans CT, Prohaska TR, Miskevics S, Ganesh SP, Weaver FM. Males aging with a spinal cord injury: prevalence of cardiovascular and metabolic conditions. Arch Phys Med Rehabil. 2012;93:90-95. https://doi.org/10.1016/j.apmr.2011.07.201.

15. Ullrich PM, Jenson MP, Loeser JD, Cardenas DD. Pain intensity, pain interference and characteristics of spinal cord injury. Spinal Cord. 2008;46:451-5. https://doi.org/10.1038/sc.2008.5.

16. Fortman A, Rutledge T, McCulloch RC, Shivpuri S, Nisenzon AN, Muse J. Satisfaction with life among veterans with spinal cord injuries completing multidisciplinary rehabilitation. Spinal Cord. 2013;51:482-6. https://doi.org/10.1038/sc.2012.172.

17. LaVela SL, Etingen B, Miskevics S, Heinemann AW. What determines low satisfaction in individuals with spinal cord injury? J Spinal Cord Med. 2018;1-9. https://doi.org/10.1080/10790268. 2018.1466480.

18. van Koppenhagen CF, Post MW, van der Woude LH, de Grppt S, de Wotte LP, van Asbeck FW, et al. Recovery of life satisfaction in persons with spinal cord injury during inpatient rehabilitation. Am J Phys Med Rehabil. 2009;88:887-95. https://doi.org/10. 1097/PHM.0b013e3181b71afe.

19. Hale-Gallardo J, Jia H, Delisle A, Levy C, Osorio V, Smith J, et al. Enhancing health and independent living for veterans with disabilities by leveraging community-based resources. J Multidiscip Health. 2017;10:41-7. https://doi.org/10.2147/jmdh. s118706.

20. Chen Y, Devivo MJ, Richards JS, Sanagustin TB. Spinal cord injury model systems: review of program and national database from 1970 to 2015. Arch Phys Med Rehabil. 2016;97:1797-804. https://doi.org/10.1016/j.apmr.2016.02.027.

21. Ware JE, Sherbourne CD. The MOS 36-Ltem short-form health survey (SF-36). Med Care. 1992;30:473-83. https://doi.org/10. 1097/00005650-199206000-00002.

22. Mchorney CA, Johne W, Anastasiae R. The MOS 36-item shortform health survey (SF-36). Med Care. 1993;31:247-63. https:// doi.org/10.1097/00005650-199303000-00006.

23. Whiteneck GG, Brooks CA, Charlifue S, Gerhart KA, Mellick D, Overholser D, et al. Guide for use of the CHART: craig handicap assessment and reporting technique [internet]. Englewood (CO): Craig Hospital; 1992. https://craighospital.org/uploads/Cra igHospital.CHARTManual.pdf.

24. Whiteneck GG, Brooks CA, Charlifue S, Gerhart KA, Mellick D, Overholser D, et al. Quantifying handicap: a new measure of long-term rehabilitation outcomes. Arch Phys Med Rehabil.
1992;73:519-26. https://www.archives-pmr.org/article/0003-9993 (92)90185-Y/pdf.

25. Diener E, Emmons RA, Larsen RJ, Griffin S. The satisfaction with life scale. J Pers Assess. 1985;49:71-5. https://doi.org/10.1207/ s15327752jpa4901_13.

26. Post MW, Leeuwen CM, Koppenhagen CF, Groot SD. Validity of the life satisfaction questions, the life satisfaction questionnaire, and the satisfaction with life scale in persons with spinal cord injury. Arch Phys Med Rehabil. 2012;93:1832-7. https://doi.org/ 10.1016/j.apmr.2012.03.025.

27. Twisk JWR. Applied longitudinal data analysis for epidemiology. Cambridge UK: Cambridge University Press; 2013.

28. Olsen A, O'Leary S. Military veterans and social security: 2010 update. Soc Secur Bull. 2011;71: 1-15. https://ssrn.com/abstract= 1831443.

29. Krause JS, Reed KS. Barriers and facilitators to employment after spinal cord injury: underlying dimensions and their relationship to labor force participation. Spinal Cord. 2010;49:285-91. https:// doi.org/10.1038/sc.2010.110.

30. Inge KJ, Cimera RE, Revell WG, Wehman PH, Seward HE. Employment outcomes for individuals with spinal cord injuries: 2011-2013. J Vocat Rehabil. 2015;42:85-96. https://doi.org/10. 3233/JVR-140726.

31. Ottomanelli L, Lind L. Review of critical factors related to employment after spinal cord injury: implications for research and vocational services. J Spinal Cord Med. 2009;32:503-31. https://www.ncbi.nlm.nih.gov/pmc/articles/PMC2792457/.

32. Krause JS, Saunders L, Staten D. Race-ethnicity, education, and employment after spinal cord injury. Rehabil Couns Bull. 2010;53:78-86. https://doi.org/10.1177/0034355209345161.

33. Ottomanelli L, Sippel JL, Cipher DJ, Goetz LL. Factors associated with employment among veterans with spinal cord injury. Spinal Cord. 2011;34:141-50. https://doi.org/10.3233/JVR-2011-0542.

34. Chen Y, He Y, DeVivo MJ. Changing demographics and injury profile of new traumatic spinal cord injuries in the United States, 1972-2014. Arch Phys Med Rehabil. 2016;97:1610-9. https://doi. org/10.1016/j.apmr.2016.03.017.

35. Wang V, Allen K, Van Houtven CH, Coffman C, Sperber N, et al. Supporting team to optimize function and independence in Veterans: a multi-study program and mixed methods protocol. Implement Sci. 2018;13:1-14. https://doi.org/10.1186/s13012018-0748-3.

36. The University of Alabama at Birmingham. National Spinal Cord Injury Model Systems (SCIMS) Database. https://www.nscisc.ua b.edu/Public_Pages/Database. 